\title{
Prevalence of recurrent aphthous ulceration in Jordanian dental patients Rima Ahmad Safadi
}

\author{
Address: Department of Oral Surgery and Medicine, Faculty of Dentistry, Jordan University of Science and Technology, Irbid, Jordan \\ Email: Rima Ahmad Safadi - rsafadi@just.edu.jo
}

Published: 22 November 2009

BMC Oral Health 2009, 9:31 doi:10.1|186/|472-683|-9-3|

This article is available from: http://www.biomedcentral.com/I472-6831/9/3।

(c) 2009 Safadi; licensee BioMed Central Ltd.

This is an Open Access article distributed under the terms of the Creative Commons Attribution License (http://creativecommons.org/licenses/by/2.0), which permits unrestricted use, distribution, and reproduction in any medium, provided the original work is properly cited.
Received: 22 April 2009

Accepted: 22 November 2009

\begin{abstract}
Background: Reviewing the literature, no studies were cited to report the prevalence of recurrent aphthous ulceration in Jordan. The aim of this study is to report the prevalence of recurrent aphthous ulceration in Jordanian subjects.

Methods: A total of 684 dental patients who attended Jordan University of Science and Technology interviewed and administered to fill questionnaires related to history, size, shape, and duration of recurrent aphthous ulceration. Other related questions were also asked.

Results: About $78 \%$ of subjects experienced recurrent aphthous ulceration. Approximately $85 \%$ of ulcers were less than one $\mathrm{cm}$ in diameter, $66 \%$ were circular in shape, $92 \%$ were painful, $82 \%$ interfered with eating, and $55 \%$ located in lips and buccal mucosa. Only $50 \%$ of participants related ulcers to stress. Sixty eight percent reported no association with tiredness and $85 \%$ no association with types of food ingested. Of the $39 \%$ who had blood tests carried out, $7 \%$ had vitamin BI 2 and $4 \%$ hemoglobin deficiency.
\end{abstract}

Conclusion: Recurrent aphthous ulceration is a common problem in Jordanian adults.

\section{Background}

Recurrent aphthous ulceration was reported as the most common inflammatory ulcerative condition of the oral mucosa. [1,2] Aphthous ulcers are classified on the basis of ulcer size into major, minor or herpetiform. [3] Minor aphthous ulcers are small (less than one $\mathrm{cm}$ in diameter), well defined, shallow, and heal within two weeks without scars. Major ulcers, however, are bigger, deeper, and take up to six weeks to heal leaving a scar behind. Herpetiform ulceration is also characterized by small (3-6 mm), shallow ulcers which takes weeks to heal, but with many numerous ulcers at once. [3]

The etiology of recurrent aphthous ulceration is not understood. [4] No principal cause has been discovered, however attacks may be precipitated by, or associated with, local trauma, stress, food hypersensitivity, hormonal changes, microorganisms, and vitamin and trace element deficiencies. [5] Systemic conditions including genetic predisposition, immune dysregulation, and family history might play a role in recurrent aphthous ulceration in some patients. [6]

A diagnosis of recurrent aphthous ulceration depends mainly on history and clinical examination. Patients with mild recurrent aphthous ulceration usually do not require any treatment for the lesion. However topical cortocosteroids therapy may be used to reduce the frequency and severity of attacks. [7] The occurrence of aphthous ulcers appears to be less frequently in smokers than in non- 
smokers. [8,9] However, an increase experience of recurrent aphthous ulcerations was reported following smoking cessation. [10] Female had predominance in aphthous ulcers. $[11,12]$ Aphthous ulcers are increased by increasing age and minor aphthous ulcers are $80 \%$ of suffered patient. [13]

The prevalence of recurrent aphthous ulceration was reported to be $40 \%$ in a sample of children of the United States. [14] Aphthous ulcers were reported to vary from 5 to $66 \%$ among different nations. [15,16] Reviewing the literature, no studies were cited to report the prevalence of recurrent aphthous ulceration in Jordan.

The aim of this study is to report the prevalence of recurrent aphthous ulceration in a sample of Jordanian subjects and to understand the independent factors that might be related to this condition.

\section{Methods}

The sample of the present study comprised dental patients who attended Jordan University of Science and Technology's Dental Teaching Center for examination and treatment at a variety of dental disciplines. No attempt was made to exclude any subject for any reason. This study was approved by the Jordan University of Science and Technology (JUST) ethics committee through the Deanship of Scientific Research at JUST. Signed consent forms were obtained from all participants before conducting the study.

Subjects were interviewed and administered and asked to fill a questionnaire specially prepared for this project. The questionnaire includes questions related to the sociodemographics of the subjects. It also includes questions related to history, size, shape and duration of recurrent aphthous ulceration. Other questions were related to management of ulceration and also related to other independent factors that might be related to the condition.

Collected data were recorded on paper forms, and were then entered, verified, processed and analyzed using a software package SPSS program version 12 (SPSS Inc; Chicago, USA 2003). The frequency distribution of recurrent aphthous ulceration was calculated. Chi-square test was also used to compare the prevalence of recurrent aphthous ulceration between categories of age, gender, education, occupation and family history of recurrent aphthous ulceration.

\section{Results}

The number of subjects invited to participate were 800 subjects. Subjects who accepted participation in the interview were 684 participants. About $45 \%$ of participants were males and $55 \%$ were females. The mean age of par- ticipants was 37.5 years and ranged from 13 years to 68 years old. The mean years of education were 12.7 years and ranged from 0 to 18 years. From those who were employed, $47 \%$ were engaged in professional occupation and $53 \%$ were non-professional workers. About $31 \%$ of participants were smokers and male smokers were found to be more prevalent (39\%) than female smokers $(24 \%)$.

Table 1 presents information related to recurrent aphthous ulceration experience among participants. Approximately $78 \%$ of participants reported that they experienced recurrent aphthous ulceration in the past. About $85 \%$ of the reported ulcerations were less than one $\mathrm{cm}$ in diameter, and about two-thirds of them were circular in shape. Approximately half of participants reported that ulcerations were single ulcerations while the other half reported them as multiple ulcerations. About 92\% subjects reported that the ulcers were painful and $82 \%$ claimed that the ulcerations interfered with food eating and swallowing. Lips and buccal mucosae were the commonest sites of ulcerations $(55 \%)$, whereas gingivae or tongues were affected in one-fifth of subjects. Floor of the mouth was the least affected site by recurrent aphthous ulceration $(8 \%)$. The duration of ulceration was reported to be less than a week for about two-thirds of participants while about $29 \%$ of participants reported that the ulceration extended up to two weeks and only minority (4\%) reported that the duration of ulceration extended longer than two weeks. Regarding family history of recurrent aphthous ulceration, $66 \%$ of subjects reported that other family member suffered previously from recurrent aphthous ulcerations. Itching prior to ulceration was experienced only by $38 \%$ of subjects.

Table 2 presents independent factors that might predispose to the condition with their management among participants. Female participants reported that they had recurrent aphthous ulceration (82\%) more than males $(73 \%)$ and the difference between the genders was statistically significant $(\mathrm{p}=0.003)$. Approximately $51 \%$ of participants reported that their recurrent aphthous ulcerations were related to stress; however, about $68 \%$ did not relate the ulceration to tiredness. Furthermore, $85 \%$ of participants did not relate the condition to eating certain types of food. Regarding blood test results, about 39\% of participants agreed to have a blood test as part of an investigation of the cause of aphthous ulcer. From those who underwent a blood test, $7 \%$ and $4 \%$ reported that they had decreased B12 vitamin and hemoglobin, respectively.

Regarding treatment of recurrent aphthous ulceration, about $41 \%$ of participants thought that the treatment of recurrent aphthous ulceration was not effective. When participants were asked how they dealt with recurrent aphthous ulceration, $63 \%$ reported the use of no treat- 
Table I: Information related to recurrent aphthous ulceration experience among participants

\begin{tabular}{|c|c|c|c|}
\hline Variable & Category & No. & $\%$ \\
\hline \multirow[t]{2}{*}{ History of aphthous ulcer } & Yes & 534 & 78.1 \\
\hline & No & 150 & 21.9 \\
\hline \multirow[t]{2}{*}{ Size of the ulcers } & $>1 \mathrm{~cm}$ & 76 & 15.4 \\
\hline & $<=1 \mathrm{~cm}$ & 418 & 84.6 \\
\hline \multirow[t]{2}{*}{ Shape of the ulcer } & Circular & 330 & 65.7 \\
\hline & Non-circular & 172 & 34.3 \\
\hline \multirow[t]{2}{*}{ Number of ulcers } & Single ulcer & 254 & 49.2 \\
\hline & Multiple ulcers & 262 & 50.8 \\
\hline \multirow[t]{2}{*}{ Are the ulcers painful } & Yes & 482 & 91.6 \\
\hline & No & 44 & 8.4 \\
\hline \multirow[t]{3}{*}{ Interfere with eating or swallowing } & Yes & 408 & 81.9 \\
\hline & No & 90 & 18.1 \\
\hline & Lip and inner cheek & 288 & 55.0 \\
\hline \multirow[t]{4}{*}{ site of the ulcers } & Floor of the mouth & 42 & 8.0 \\
\hline & Gingiva & 96 & 18.3 \\
\hline & Tongue & 98 & 18.7 \\
\hline & $<7$ days & 336 & 66.9 \\
\hline \multirow[t]{2}{*}{ Duration of the ulcers } & $7-14$ days & 146 & 29.1 \\
\hline & $>14$ days & 20 & 4.0 \\
\hline \multirow[t]{2}{*}{ Itching prior ulceration } & Yes & 190 & 37.5 \\
\hline & No & 316 & 62.5 \\
\hline \multirow[t]{2}{*}{ Any other family member suffering from recurrent aphthous ulcerations } & Yes & 408 & 66.4 \\
\hline & No & 206 & 33.6 \\
\hline
\end{tabular}

ment and just to live with it. However, about 20\% used painkillers and antibiotic medications without medical consultation. A small percentage of participants used steroids $(6 \%)$ and about only $12 \%$ consulted dentists for the ulceration. Those who did not consult dentists, 67\% thought that aphthous is a simple problem and did not required dental consultation. Approximately 17\% thought recurrent aphthous ulceration is not a dental problem and $16 \%$ thought that treatment for recurrent aphthous ulcerations is not working and they were tired from visiting dentists. 
Table 2: Related independent factors and management of recurrent aphthous ulceration among participants

\begin{tabular}{|c|c|c|c|}
\hline Variable & Category & No. & $\%$ \\
\hline \multirow[t]{2}{*}{ Gender with history of ulceration } & Male & 226 & 72.9 \\
\hline & Female & 308 & 82.4 \\
\hline \multirow[t]{2}{*}{ Related to stress } & Yes & 188 & 51.1 \\
\hline & No & 180 & 48.9 \\
\hline \multirow[t]{2}{*}{ Related to tiredness } & Yes & 119 & 32.3 \\
\hline & No & 249 & 67.7 \\
\hline \multirow[t]{2}{*}{ Associate with certain types of food } & Yes & 76 & 14.6 \\
\hline & No & 444 & 85.4 \\
\hline \multirow[t]{4}{*}{ Blood testing for aphthous } & Blood not tested & 414 & 60.5 \\
\hline & Blood tested normal & 194 & 28.4 \\
\hline & Decreased B 12 & 50 & 7.3 \\
\hline & Decreased hemoglobin & 26 & 3.8 \\
\hline \multirow[t]{2}{*}{ Do you think treatment of aphthous effective } & Yes & 174 & 59.2 \\
\hline & No & 120 & 40.8 \\
\hline \multirow[t]{4}{*}{ Type of treatment used for aphthous ulcers } & Live with it without treatment & 322 & 62.9 \\
\hline & Use of pain killer and antibiotics without dental consultation & 100 & 19.5 \\
\hline & Consult dentists & 60 & 11.7 \\
\hline & Use of steroids/cortisones & 30 & 5.9 \\
\hline \multirow[t]{3}{*}{ Reason for not consulting dentists for aphthous } & It is a simple known problem & 304 & 67.3 \\
\hline & Recurrent aphthous ulceration is not dental problem & 76 & 16.8 \\
\hline & Dental treatment is not effective & 72 & 15.9 \\
\hline
\end{tabular}

\section{Discussion}

Recurrent aphthous ulceration is quite common condition affecting the oral cavity, yet it is an important condition since it can be distressing and cause suffering and pain. In addition, it interferes with normal life activities by affecting eating and swallowing of sufferers. Studying the prevalence of recurrent aphthous ulceration is important since it gives insight into the proportion of people who suffer from the condition as well as the possible causal factors.
Jordan University of Science and Technology provide freeof-charge dental examination and treatment to all patients regardless of their dental insurance. This service is part of dental student training on most of dental disciplines. The results of this study reflect the prevalence of recurrent aphthous ulceration only in patients attended dental clinics at JUST. However, there is no reason to believe that this group of patients is different from other residents in north Jordan. 
Subjects were asked, "Have you ever suffered recurrent aphthous ulceration in your life?". This type of studies depends mainly on patients' recollection of the condition in the past. Few patients were considered not having aphthous ulcers because they could no recall if they had this condition in their life, therefore recurrent aphthous ulceration occurrence for those patients might be unrealistic.

Comparison of the present results with those from previous studies should be undertaken with caution due to differences in the study design, sample size, and geographical location. The result of this study was higher than that reported from USA, [17] and many other countries. [18] This could be explained by that Jordanian subjects might be different than other populations in term of genetic predisposition, stress, lifestyle and other related factors.

Reviewing the literature, approximately $80 \%$ of patients with recurrent aphthous ulcerations were exhibiting minor type. [18] This is consistent with the results of the present study. Jordanian females were found to have more ulceration than males. These results are also in line with other studies. [11,17]

This study is the first to describe the prevalence and distribution of recurrent aphthous ulceration among Jordanian residents. No other publication was found to address the prevalence of this condition among Jordanian adults.

\section{Conclusion}

Understanding the prevalence and distribution of recurrent aphthous ulceration among Jordanian population will give an indication about the proportion of people who suffer the condition and who need dental management. Knowledge about the increased proportion of Jordanian people with recurrent aphthous ulceration might help dental practitioner in reaching the proper diagnosis of the ulcers affecting oral cavities and in providing information to patient to enhance their awareness about the condition.

\section{Competing interests}

There are no competing interests (political, personal, religious, ideological, academic, intellectual, commercial or any other) to declare in relation to this manuscript.

\section{Authors' contributions}

All work is the solely work of the author of this study.

\section{Acknowledgements}

I would like to acknowledge the contribution of Professor A. Hadi Hamasha in the analysis and interpretation of data and also in revising critically the manuscript.

\section{References}

I. Witman PM, Rogers RS: Pediatric oral medicine. Dermatol Clin 2003, 21 : 157-170.

2. Scully C, Porter S: Oral mucosal disease: recurrent aphthous stomatitis. Br J Oral Maxillofac Surg 2008, 46:198-206.

3. Sciubba Jj: Oral mucosal diseases in the office setting--part I: Aphthous stomatitis and herpes simplex infections. Gen Dent 2007, 55:347-354.

4. Rogers RS: Recurrent aphthous stomatitis: clinical characteristics and associated systemic disorders. Semin Cutan Med Surg 1997, 16:278-283.

5. Natah SS, Konttinen YT, Enattah NS, Ashammakhi N, Sharkey KA, Häyrinen-Immonen R: Recurrent aphthous ulcers today: a review of the growing knowledge. Int J Oral Maxillofac Surg 2004, 33:22I-234.

6. Rhee SH, Kim YB, Lee ES: Comparison of Behcet's disease and recurrent aphthous ulcer according to characteristics of gastrointestinal symptoms. J Korean Med Sci 2005, 20:97I-976.

7. Sedghizadeh PP, Shuler CF, Allen CM, Beck FM, Kalmar JR: Celiac disease and recurrent aphthous stomatitis: a report and review of the literature. Oral Surg Oral Med Oral Pathol Oral Radiol Endod 2002, 94:474-478.

8. Grady D, Ernster VL, Stillman L, Greenspan J: Smokeless tobacco use prevents aphthous stomatitis. Oral Surg Oral Med Oral Pathol 1992, 74:463-465.

9. McCullough MJ, Abdel-Hafeth S, Scully C: Recurrent aphthous stomatitis revisited; clinical features, associations, and new association with infant feeding practices? J Oral Pathol Me 2007, 36:615-620.

10. Ussher M, West R, Steptoe A, McEwen A: Increase in common cold symptoms and mouth ulcers following smoking cessation. Tob Control 2003, 1 2:86-88.

II. Pongissawaranun W, Laohapand P: Epidemiologic study on recurrent aphthous stomatitis in a Thai dental patient population. Community Dent Oral Epidemiol 1991, 19:52-53.

12. Field EA, Brookes V, Tyldesley WR: Recurrent aphthous ulceration in children--a review. Int J Paediatr Dent 1992, 2: I- 10.

13. Peretz B: Major recurrent aphthous stomatitis in an I I-yearold girl: case report. J Clin Pediatr Dent 1994, 18:309-312.

14. Shulman JD: Prevalence of oral mucosal lesions in children and youths in the USA. Int J Paediatr Dent 2005, 15:89-97.

15. Porter SR, Scully C, Pedersen A: Recurrent aphthous stomatitis. Crit Rev Oral Biol Med 1998, 9:306-32I.

16. Davatchi F, Tehrani-Banihashemi A, Jamshidi AR, Chams-Davatchi C, Gholami J, Moradi M, Akhlaghi M, Foroozanfar MH, Barghamdi M, Noorolahzadeh E, Samadi F, Hadj-Aliloo M, Ghaznavi K, Ghaznavi K, Soroosh M, Khabazi A, Salari AH, Sharif SK, Karimifar M, Salessi M, Essalat-Manesh K, Nadji A, Shahram F: The prevalence of oral aphthosis in a normal population in Iran: a WHO-ILAR COPCORD study. Arch Iran Med 2008, I I:207-209.

17. Shulman JD: An exploration of point, annual, and lifetime prevalence in characterizing recurrent aphthous stomatitis in USA children and youths. J Oral Pathol Med 2004, 33:558-566.

18. Field EA, Allan RB: Review article: oral ulceration--aetiopathogenesis, clinical diagnosis and management in the gastrointestinal clinic. Aliment Pharmacol Ther 2003, 18:949-962.

\section{Pre-publication history}

The pre-publication history for this paper can be accessed here:

http://www.biomedcentral.com/1472-6831/9/31/prepub 